\title{
Role of androgens, progestins and tibolone in the treatment of menopausal symptoms: a review of the clinical evidence
}

\author{
Maria Garefalakis \\ Martha Hickey \\ School of Women's and Infants' Health \\ The University of Western Australia, \\ King Edward Memorial Hospital, \\ Subiaco, Western Australia, Australia
}

\begin{abstract}
Estrogen-containing hormone therapy (HT) is the most widely prescribed and wellestablished treatment for menopausal symptoms. High quality evidence confirms that estrogen effectively treats hot flushes, night sweats and vaginal dryness. Progestins are combined with estrogen to prevent endometrial hyperplasia and are sometimes used alone for hot flushes, but are less effective than estrogen for this purpose. Data are conflicting regarding the role of androgens for improving libido and well-being. The synthetic steroid tibolone is widely used in Europe and Australasia and effectively treats hot flushes and vaginal dryness. Tibolone may improve libido more effectively than estrogen containing HT in some women. We summarize the data from studies addressing the efficacy, benefits, and risks of androgens, progestins and tibolone in the treatment of menopausal symptoms.
\end{abstract}

Keywords: androgens, testosterone, progestins, tibolone, menopause, therapeutic

\section{Introduction}

Therapeutic estrogens include conjugated equine estrogens, synthetically derived piperazine estrone sulphate, estriol, dienoestrol, micronized estradiol and estradiol valerate.

Estradiol may also be given transdermally as a patch or gel, as a slow release percutaneous implant, and more recently as an intranasal spray. Intravaginal estrogens include topical estradiol in the form of a ring or pessary, estriol in pessary or cream form, dienoestrol and conjugated estrogens in the form of creams.

In some countries there is increasing prescribing of a combination of estradiol, estrone, and estriol as buccal lozenges or 'troches', which are formulated by private compounding pharmacists. The efficacy, safety, and pharmacodynamic profile of these lozenges are unknown and should not be recommended for clinical use.

Progestins are synthetic analogues of progesterone that have been developed to overcome the problems of poor oral absorption of progesterone and its rapid first-pass metabolism in the liver.

Androgens are steroids based on the structure of testosterone. Parenteral testosterone has a very short duration of action and oral bioavailability is negligible. Topical, implantable, and depot testosterone formulations and synthetic orally active androgens have been developed.

Tibolone (Livial ${ }^{\circledR}$; Organon, Oss, Netherlands) is prescribed in over 70 countries for the treatment of menopausal symptoms and prevention of osteoporosis. Classified as a selective tissue estrogenic action regulator (STEAR), it is a synthetic steroid that has various metabolites with tissue-specific estrogenic, progestinic, and androgenic actions (Albertazzi et al 1998). 


\section{Menopausal symptoms}

The vast majority of women going through menopause will experience symptoms related to the hormonal changes during this transition. Of these, vasomotor symptoms such as hot flushes and night sweats are the most characteristic, and are the main reason why women seek treatment (Kronenberg 1994).

\section{Vasomotor symptoms}

Vasomotor symptoms, in particular hot flushes, are the most characteristic manifestation of the menopause, occurring in almost $80 \%$ of women of whom about $20 \%$ find them intolerable (WHO 1966; Kronenberg 1990).

Hot flashes are described as the sudden sensation of heat over the body, particularly in the face, neck, or chest and can be accompanied by sweating, flushing, palpitations and anxiety. Night sweats may occur with hot flashes or independently and can disrupt sleep. Approximately one third of women will continue to have vasomotor symptoms for up to five years and some women for even longer (Kronenberg 1990).

\section{Estrogen (ET) and estrogen - progestin therapy (EPT)}

Estrogen is generally prescribed and as single therapy to hysterectomized women and combined with a progestin in women with an intact uterus to prevent endometrial hyperplasia.

Hormone therapy is highly effective in the treatment of menopausal vasomotor symptoms. In quality randomized, placebo controlled trials, estrogen alone reduces vasomotor symptoms by $65 \%$ (OR $0.35,0.22-0.56)$ and combined HT by $90 \%$ (OR $0.10,0.06-0.19)$. Hence, whilst direct comparative trials are lacking, combined HT appears to be more effective at treating vasomotor symptoms than estrogen alone (SlowinskaSrzednicka et al 1992). Importantly, the mean placebo effect was $51 \%$ in these trials. Alternative treatments for vasomotor symptoms must be compared against this high placebo response, which may be partly due to symptom fluctuation around perimenopause and gradual resolution of symptoms post-menopause (Slowinska-Srzednicka et al 1992).

Oral estrogen therapy increases the plasma protein sex hormone binding globulin (SHBG) to a greater extent than non-orally administered estrogens (Pasqualini et al 1996) and this may result in a clinically significant reduction in the bioavailability of sex steroids, including testosterone.

\section{Progestins}

Progestins delivered via a variety of routes are effective in the treatment of menopausal hot flashes. Oral progestins are superior to placebo in treating hot flashes, but are less effective than estrogen (Prestwood et al 2003). Progestins do not affect clotting factors and hence may be an option for women at increased risk of thrombosis (Schindler 2003).

Reduction in vasomotor symptoms has been demonstrated with daily doses of 10 to $20 \mathrm{mg}$ of oral medroxyprogesterone acetate (MPA) and $20 \mathrm{mg}$ twice a day of oral megestrol acetate (Schiff et al 1980; Loprinzi et al 1994). Depo medroxyprogesterone acetate is effective in treating hot flashes in breast cancer patients (Loprinzi et al 2006), but the safety of DMPA after breast cancer is not established.

The evidence of whether transdermal progestins are effective in treating menopausal hot flashes is conflicting (Leonetti et al 1999; Wren et al 2003).

Concerns about the use of progestin include the observation from large randomized controlled trials (RCTs) that the addition of progestins to estrogen might increase the risk of breast cancer (Rossouw et al 2002). Also, the addition to progestin to estrogen in menopausal HRT increases breast density at mammography and increased breast density is a risk factor for breast cancer (Warren 2004).

Progestins vary in their clinical effects and endocrine properties (see Table 1). This may also impact on their efficacy and side effects in the management of menopausal symptoms.

\section{Tibolone}

Tibolone is a synthetic prohormone with weak estrogenic, progestinic, and androgenic actions. It does not stimulate the endometrium so additional progestins are not required. A dose-finding study demonstrated that tibolone was significantly more effective than placebo for the management of hot flushes and sweating, and reported that a daily dose of

Table I Biological activities of progesterone and progestins

\begin{tabular}{|c|c|c|c|c|c|c|}
\hline Progestin & Anti E & $\mathbf{E}$ & $\mathbf{A}$ & Anti A & Gluco & Anti min \\
\hline Progesterone & + & - & - & \pm & + & + \\
\hline Dydrogesterone & + & - & - & \pm & - & \pm \\
\hline \multicolumn{7}{|l|}{ I $7 \alpha-\mathrm{OH}$-derivatives } \\
\hline Cyproterone acetate & + & - & - & ++ & + & - \\
\hline MPA & + & - & \pm & - & + & - \\
\hline \multicolumn{7}{|l|}{$\begin{array}{l}\text { Spironolactone } \\
\text { derivatives }\end{array}$} \\
\hline Drospirenone & + & - & - & + & - & + \\
\hline \multirow{2}{*}{\multicolumn{7}{|c|}{$\begin{array}{l}\text { 19-nortestosterone } \\
\text { derivatives }\end{array}$}} \\
\hline & & & & & & \\
\hline Norethisterone & + & + & + & - & - & - \\
\hline Levonorgestrel & + & - & + & - & - & - \\
\hline Dienogest & \pm & \pm & - & + & - & - \\
\hline
\end{tabular}

Derived from Schindler et al (2003).

Abbreviations: Ant E, anti-estrogenic; E, estrogenic;A, androgenic;Anti A, antandrogenic; Gluco, glucocorticoid; Anti min, antimineralocorticoid. 
$2.5 \mathrm{mg}$ was clinically optimal with respect to symptom relief, adverse events, and acceptability (Landgren et al 2002). There are limited data comparing tibolone with estrogen-containing HRT, but in small studies tibolone effectively reduces hot flashes and improves vaginal dryness with a similar efficacy to estrogen (Baracat 2002; Modelska and Cummings 2002). Tibolone does not increase mammographic density (Valdivia et al 2004). Unlike estrogen, tibolone reduces SHBG, and hence may increase free circulating testosterone. This effect plus tibolone's androgenic properties are believed to enhance sexual function to a greater extent than ET/EPT (Egarter et al 2002). However, this is yet to be demonstrated with validated instruments in an adequately powered RCT. Tibolone increases bone density but fracture data are not yet published.

Tibolone suppresses the endometrium and is associated with fewer days of bleeding and spotting than combined HRT (Archer 2007).

A significant fall in HDL cholesterol can occur with tibolone therapy. The clinical implication of the effect of tibolone on lipid metabolism and hemostasis is unclear. Definite conclusions with regard to risks for cardiovascular disease or venous thromboembolism cannot be drawn from trials to date and long-term effects are unknown.

Data from the Million Women study suggested that current use of tibolone is associated with an increased risk of breast and endometrial cancer than that seen with nonusers or previous users. Although these findings have been questioned because of likely selection bias due to prescribing practices and confirmation in a randomised controlled trial is required (Million Women Study Collaborators 2003, 2005). Preliminary data suggested that tibolone may be safely used following breast cancer (Antoine et al 2007), but this has not been confirmed in larger scale randomised controlled trials (www.organon.com).

\section{Sexual dysfunction}

Sexual difficulties are complex in origin. Poor arousal, vaginal dryness, dyspareunia, and orgasmic difficulties are more common in the menopausal years. Simple vaginal lubricants and moisturisers, psychological intervention, counseling, or sex therapy should be considered. There is a paucity of evidence on the effect of progestins alone on sexual functioning.

\section{Androgens}

RCTs have demonstrated improvement in measurements of sexual function with various types of combined estrogen - testosterone compared with estrogen alone or placebo.

As stated above, trials of women with spontaneous and surgical menopause showed improvement in self-reported sexual enjoyment, desire, and arousal when testosterone was added to ET/EPT (Dow et al 1983; Sherwin et al 1985; Davis et al 1995; Sarrel et al 1998; Shifren 2002; Lobo et al 2003)

RCTs of women with surgical menopause demonstrated increased sexual desire and frequency of satisfying sexual activity in women using $300 \mathrm{mcg}$ daily testosterone patches (Braunstein et al 2000; Buster et al 2005).

It has been suggested that to be effective, androgen levels must be increased above normal (Cameron and Braunstein 2004).

Total and free testosterone levels decline with age, prior to the menopause (Paganini-Hill and Henderson 1989) and do not vary across the menopause transition in healthy women (Green et al 1996). However, oophorectomy is associated with a significant decline in circulating testosterone levels (Beresford et al 1997).

\section{Testosterone}

Testosterone is the most potent female androgen. The primary indication for the use of supplemental testosterone has been the treatment of low libido in post-menopausal women. However, the question of whether there is a syndrome of female androgen insufficiency and whether supplementary androgens have a beneficial effect on libido, energy or sense of wellbeing in pre and postmenopausal women remains unresolved. In the absence of high quality evidence expert opinion is divided. Whilst some high quality RCTs have demonstrated that increases in total and free testosterone in the physiologic range in postmenopausal women are associated with improvement in sexual satisfaction, general well-being, and mood. (Davis et al 2006), other studies have not confirmed this. There has been a lack of standardization in the measurement of female sexual function which makes direct comparisons between studies difficult.

A recent consensus statement from the Endocrine Society recommend against making a diagnosis of androgen deficiency in women at present because of the lack of a welldefined clinical syndrome and normative data on total or free testosterone levels across the lifespan that can be used to define the disorder. They recognized that there is evidence for short-term efficacy of testosterone in selected populations, such as surgically menopausal women, but advised against the generalized use of testosterone by women, because the indications are inadequate and evidence of safety in long-term studies is lacking (Wierman et al 2006). In contrast, other expert groups have argued there are ample data to suggest that adrenal androgens play a role in the development of axillary 
and pubic hair, and that testosterone is critical for women's libido and sexual function (Traish et al 2007).

In addition, there are a number of practical restrictions to the diagnosis and management. No lower limit of total or free testosterone has been shown to be diagnostic of female androgen insufficiency and there is no "normal range" for postmenopausal women. Further, most available assays are unable to accurately measure testosterone in the lower female range. Most circulating testosterone is protein-bound but only the free fraction is clinically active. Hence an estimate of free testosterone is thought to be the most useful measure of endogenous testosterone levels. However, commonly available direct free testosterone assays are notoriously imprecise (Wells et al 2002), and it is generally agreed that free testosterone is most reliably calculated by the laboratory using the Sodergard equation if both total testosterone and sex hormone binding globulin are known (Riphagen 2000).

A further confounding factor for clinical practice is that circulating estrogen levels will impact on free testosterone via an increase in SHBG. Most investigators recommend that androgen therapy should be offered only when the patient continues to have problems while receiving adequate estrogen replacement therapy (Braunstein 2002).

Since the measurement of serum testosterone is fraught, the main indication for measurement should be to exclude women from therapy because of a mid range or higher testosterone value or to ensure that levels do not become supraphysiological if exogenous androgens are prescribed.

The decision to prescribe testosterone to a woman needs to be based upon clinical assessment, which includes exclusion of factors such as fundamental relationship difficulties, clinical depression and other common causes of low wellbeing during midlife such as iron deficiency and thyroid disease. Testosterone preparations include a transdermal patch, cream, gel, and spray.

Safety data for testosterone and combined estrogenandrogen therapy in postmenopausal women are lacking. High levels of endogenous testosterone (and estrogen) in postmenopausal woman are linked with an increased risk of breast cancer. (Hankinson and Eliasson 2007) and there are no data from large RCTs on the effects of supplemental testosterone on breast cancer risk. Side effects of exogenous testosterone include acne and hirsutism. Long-term use may be associated with adverse clinical and metabolic as well as cosmetic effects. A decrease in HDL cholesterol has been documented with the addition of methyltestosterone and testosterone implants to hormonal therapies (Castelo-Branco et al 2000; Somboonporn et al 2005).

\section{DHEA}

Dehydroepiandrosterone (DHEA) is a female androgen increasingly available commercially as a supplement aimed at improving libido and well-being in post-menopausal women. However, there is scant evidence to support the use of DHEA for this purpose, and safety data for DHEA therapy are lacking. DHEA and its sulfate DHEAS are the most abundant circulating sex steroid hormones in women, providing a large precursor reservoir for the intracellular production of androgens and oestrogens in non-reproductive tissues. Levels of DHEA and DHEAS decline with age. In premenopausal women, levels of DHEA correlate with feelings of vitality (Bell et al 2006). It has been proposed that restoring the circulating levels of these steroids to those found in young people may have anti-aging effects and improve well-being and sexual function. However, this is not supported by the published literature and there is currently no clear clinical role for DHEA (Panjari and Davis 2007).

\section{Vaginal dryness}

Approximately $50 \%$ of post menopausal women suffer symptoms of urogenital atrophy. This may include vaginal dryness, dyspareunia and recurrent urinary tract infections (Maclennan et al 2002; Boothby et al 2004). Topical (vaginal) estrogen effectively relieves vaginal dryness and atrophy. However, although the urogenital tract is estrogen sensitive, urinary incontinence may not respond to systemic estrogen and observational data from the Nurses Health Study suggests that hormone therapy may even worsen urinary incontinence (Cardozo et al 1998; Simpson et al 2000).

Neither androgens nor progestins have been shown to improve vaginal dryness or improve urogenital symptoms. For women with vaginal dryness who wish to avoid hormones, vaginal lubricants such as Replens ${ }^{\circledR}$ (WarnerLambert, Morris Plains, NJ) may be helpful, but are not as effective as topical estrogens. (Nachtigall 1994; Bygdeman and Swahn 1996)

\section{Tibolone}

RCTs assessing the effects of tibolone on sexual function have demonstrated significant improvement in the physiological aspects of sexual function in postmenopausal women, including those who have undergone bilateral oophorectomy, such as vaginal blood flow and vaginal lubrication. They have also reported increased sexual interest and desire in postmenopausal women taking tibolone compared with placebo (Laan and van Lunsen 2001; Egarter et al 2002). 
In two other trials, tibolone was compared with combined estradiol-norethisterone acetate (E2/NETA). Scores measuring improvement of sexual function with regard to frequency, satisfaction, and enjoyment was higher in women taking tibolone versus those taking E2/NETA (Nathorst-Böös and Hammar 1997; Doren et al 2001).

If tibolone improves sexual function, it will be important to determine whether it does so by increasing free testosterone in women with low testosterone concentrations or in all women regardless of androgen levels (Modelska and Cummings 2002).

\section{Mood and cognitive disturbances}

A range of other symptoms, including depression, nervousness, agitation, insomnia, arthralgia, and poor concentration are associated with the menopause (Bachmann 1998), but the relationship between these symptoms and low estrogen is more difficult to determine. Such psychological and mood changes around the time of menopause may be the result of a complex interplay between environmental stimuli and other factors such as sleep disturbance and fatigue. Sleep disturbance is a pervasive and distressing menopausal symptom and may occur independently of hot flushes and night sweats (Cardozo et al 1998). A community-based longitudinal study gave no support for mood symptoms being part of the menopausal syndrome (Avis et al 1994; Baker 1994; Khan et al 1994; Dennerstein et al 2004).

Any improvements in these symptoms or in general wellbeing noted while taking ET/EPT may be due to improvements in vasomotor symptoms, urogenital symptoms, sexual function, and quality of sleep (Brown et al 2001).

Findings of observational studies suggest that hormone therapy could improve or preserve cognitive function in women with and without dementia, respectively (McBee et al 1997; Carlson et al 2001; Lokkegaard 2002). Furthermore, results of a meta-analysis (Le Blanc et al 2001) indicate that women with menopausal symptoms who take ET/EPT have better verbal memory, vigilance, reasoning, and motor speed, than those who do not. However, initiation of ET/EPT in women older than age 65 years did not prevent dementia or enhance cognition in the primary prevention of dementia part of WHI (WHIMS) (Espeland et al 2004; Shumaker et al 2004), but was instead associated with an increased rate of cognitive decline compared with placebo (Shumaker et al 2003).

Data from RCTs (Mulnard et al 2000) of women with established dementia indicate that ET/EPT neither increases disease progression nor improves symptoms. The cognitive response to HRT might vary according to genotype; only individuals who do not carry the apolipoprotein E (APOE) genotype (the major genetic risk factor for Alzheimer's disease) are protected by hormone therapy (Burkhardt et al 2004). Whether these observations about mental state and HRT can be applied to women of all ages and irrespective of different estrogen/progestin combinations or modes of delivery is not known.

Generally, hormone therapy should not be recommended for the preservation of cognitive function or the prevention of dementia (Andrews et al 2004; Naftolin et al 2004; RANZCOG 2004). Furthermore, women aged older than 65 years should be made aware that commencement of ET/ EPT at such a late stage could result in a worsening of their cognitive capacity (Naftolin et al 2004).

There is little evidence of the beneficial effects of testosterone on mood or sense of well-being. One study measured improvements in well-being scores in women with surgically induced menopause using $300 \mathrm{mcg}$ testosterone patches with oral conjugated equine estrogens (The North American Menopause Society 2005; Somboonporn et al 2005). One small trial of cognition in postmenopausal women, using building memory tasks, reported a decline in scores in women using ET but a maintenance in those using combined oral estrogen-methyltestosterone (Wisniewski et al 2002).

Progestins may lead to increased adverse effects on mood when added to estrogen therapy, in a dose-dependent manner (Sherwin 1991). Another study has shown that addition of progestins improved memory above what was obtained by estrogen alone. They conclude that the effect did not depend on improvement of mood since the latter worsened during the progestinic phase of EPT (Natale et al 2001).

Published studies have reported beneficial effects of tibolone on mood (Ross et al 1999; Davis 2002).

\section{Disclosures}

Dr Maria Garefalakis has undertaken clinical research sponsored by Organon, Pfizer, GlaxoSmithKline and Schering $\mathrm{AG}$ and has been sponsored by these companies to attend international meetings. She has received an honorarium for speaking at a symposium sponsored by Astrazeneca.

Dr Martha Hickey has been reimbursed for attending symposia by Wyeth, Organon, and Novo Nordisk; has also received honoraria for speaking at symposia sponsored by pharmaceutical companies for national and international meetings from Novo Nordisk, Wyeth, Schering and Organon; and is undertaking clinical research sponsored by Organon, 
Pfizer and Schering AG. She has received unrestricted educational grants from Astra Zeneca and Organon

\section{References}

Albertazzi P, Di Micco R, Zanardi E. 1998. Tibolone: a review. Maturitas, 30:295-305.

Anderson GL, Limacher M, Assaf AR, et al. 2004. Effects of conjugated equine estrogen in postmenopausal women with hysterectomy: The Women's Health Initiative randomized controlled trial. JAMA, 291:1701-12

Andrews H, Christie B, Colledge N, et al. 2004. Consensus Statement. JR Coll Physicians Edinb, 34 (suppl 13):2-3.

Antoine C, Liebens F, Carly B, et al. 2007. Safety of alternative treatments for menopausal symptoms after breast cancer: a qualitative systematic review. Climacteric, 10:23-6.

Antunes CMF, Stolley PD, Rosenstein MB. 1979. Endometrial cancer and estrogen use: report of a large case control study. $N$ Engl J Med, 300:9-13.

Archer DF, Hendrix S, Gallagher JC, et al. 2007. Endometrial effects of tibolone. J Clin Endocrinol Metab; 92:911-18.

Avis NE, Brambilla D, McKinlay SM, et al. 1994. A longitudinal analysis of the association between menopause and depression. Ann Epidemiol, 4:214-20

Baracat ECBI, Giordano MG, Haidar MA, et al. 2002. A randomized, openlabel study of conjugated equine estrogens plus medroxyprogesterone acetate versus tibolone:effects on symptom control, bleeding pattern, lipid profile and tolerability. Climacteric, 5:60-69.

Bachmann GA. 1998. The clinical platform for the 17 beta-estradiol vaginal releasing ring. Am J Obstet Gynecol, 178:S257-60.

Baker V. 1994. Alternatives to oral oestrogen replacement:transdermal patches, percutaneous gels, vaginal creams and rings, implants, other methods of delivery. Obstet Gynecol Clin North Am, 21:271-97.

Barnhart KT, Freeman E, Grisso JA, et al. 1999. The effect of dehydroepiandrosterone supplementation to symptomatic perimenopausal women on serum endocrine profiles, lipid parameters, and health-related quality of life. J Clin Endocrinol Metab, 84:3896-902.

Baulieu EE, Thomas G, LeGrain S, et al. 2000. Dehydroepiandrosterone (DHEA) DHEA sulfate and aging:contribution of the DHEA Age Study to a sociobiomedical issue. Proc Natl Acad Sci USA, 97:4279-84.

Beckmann M, Foidart JM, Bundred NJ, et al. 2006. LIBERATE trial: A safety study of tibolone in breast cancer surgery patients - design and baseline date. German Medical Science. Meeting [abstract online] Accessed September 2006. URL: http://www.egms.de/en/meetings/ dkk2006/06dkk011.shtml.

Bell RJ, Donath S, Davison SL, Davis SR. 2006. Endogenous androgen levels and well-being:differences between premenopausal and postmenopausal women. Menopause, 13:65-71.

Beresford SAA, Weiss NS, Voigt LF, et al. 1997. Risk of endometrial cancer in relation to use of oestrogen combined with cyclic progestin therapy in postmenopausal women. Lancet, 349:458-61.

Bjarnason K, Cerin A, Lindgren R, Weber T. 1999. Adverse endometrial effects during long cycle hormone replacement therapy. Maturitas, 32:161-70.

Boothby LA, Doering PL, Kipersztok S. 2004. Bioidentical hormone therapy:a review. Menopause, 11:356-67.

Braunstein GD. 2002. Androgen insufficiency in women:summary of critical issues. Fertil Steril, 77:S94-9.

Braunstein GD, Sundwall DA, Katz M, et al. 2000. Safety and efficacy of a testosterone patch for the treatment of hypoactive sexual desire disorder in surgically menopausal women:a randomized, placebo-controlled trial. Arch Intern Med, 165:1582-9

Brown JS, Vittinghoff E, Kanaya AM, et al. 2001. Urinary tract infections in postmenopausal women:effect of hormone therapy and risk factors. Obstet Gynecol, 98:1045-52

Bruce D, Robinson J, Rymer J. 2004. Long-term effects of tibolone on the endometrium as assessed by bleeding episodes, transvaginal scan and endometrial biopsy. Climacteric, 7:261-6
Burkhardt MS, Foster JK, Laws SM, et al. 2004. Oestrogen replacement therapy may improve memory functioning in the absence of APOE epsilon4. J Alzheimers Dis, 6:221-8.

Buster JE, Kingsberg SA, Aguirre O, et al. 2005. Testosterone patch for low sexual desire in surgically menopausal women:a randomized trial. Obstet Gynecol, 105:944-52.

Bygdeman M, Swahn ML. 1996. Replens versus dienoestrol cream in the symptomatic treatment of vaginal atrophy in postmenopausal women. Maturitas, 23:259-63.

Cameron DR, Braunstein GD. 2004. Androgen replacement therapy in women. Fertil Steril, 82:273-89.

Cardozo L, Bachmann G, McClish D et al. 1998. Meta-analysis of estrogen therapy in the management of urogenital atrophy in postmenopausal women:second report of the Hormones and Urogenital Therapy Committee. Obstet Gynecol, 92:722-7

Carlson MC, Zandi PP, Plassman BL, et al. 2001. Hormone replacement therapy and reduced cognitive decline in older women:the Cache County Study. Neurology, 57:2210-6.

Castelo-Branco C, Vicente JJ, Figueras F, et al. 2000. Comparative effects of estrogens plus androgens and tibolone on bone, lipid pattern and sexuality in postmenopausal women. Maturitas, 34:161-8.

Colacurci N, Mele P, Costa V, et al. 1998. Effects of tibolone on the breast. Eur J Obstet Gynecol Reprod Biol, 80:235-8.

Davis SR, McCloud P, Strauss BJ, et al. 1995. Testosterone enhances estradiol's effects on postmenopausal bone density and sexuality. Maturitas, 21:227-36.

Davis SR. 2002. The effects of tibolone on mood and libido. Menopause, 9:162-70

Davis SR, Goldstart R, Papalia MA. 2006. Effects of aromatase inhibition on sexual function and well-being in postmenopausal women treated with testosterone:a randomized, placebo-controlled trial. Menopause, $13: 37-45$

Dennerstein L, Guthrie JR, Clark M, Lehert P, Henderson VW. 2004. A population-based study of depressed mood in the middle-aged, Australian-born women. Menopause, 11:563-8.

Dimitriakis C, Jones RA, Liu A, et al. 2004. Breast cancer incidence in postmenopausal women using testosterone in addition to usual hormone therapy. Menopause, 11:531-5

Dören M, Ruebig A, Holzgreve W. 2001. Differential effects on the androgen status of postmenopausal women treated with tibolone and continuous combined estradiol and norethindrone acetate replacement therapy. Fertil Steril, 75:554-8.

Dow MG, Hart DM, Forrest CA. 1983. Hormonal treatments of sexual unresponsiveness in postmenopausal women:a comparative study. $\mathrm{Br}$ J Obstet Gynaecol, 90:361-6.

Egarter C, Topcuoglu AM, Vogl S, et al. 2002. Hormone replacement therapy with tibolone:effects on sexual functioning in postmenopausal women. Acta Obstetricia et Gynecologica Scandinavica, 81:649-53.

Espeland MA, Rapp SR, Shumaker SA, et al. 2004. Conjugated equine estrogens and global cognitive function in postmenopausal women:Women's Health Initiative Memory Study. JAMA, 291:2959-68.

Ginsburg J, Prelevic G. 1995. Tibolone in postmenopausal women with a history of breast carcinoma. J Br Menopause Soc, 1:24-5.

Green PK, Weiss NS, McKnight B, et al. 1996. Risk of endometrial cancer following cessation of menopausal hormone use. Cancer Causes Control, 7:575-80

Hammar M, Christau S, Nathorst-Böös J, et al. 1998. A double-blind, randomised trial comparing the effects of tibolone and continuous combined hormone replacement therapy in postmenopausal women with menopausal symptoms. Br J Obstet Gynaecol, 105:904-11.

Hankinson SE, Eliassen AH. 2007. Endogenous estrogen, testosterone and progesterone levels in relation to breast cancer risk. J Steroid Biochem Mol Biol, 106:24-30.

Henderson BE, Casagrande JT, Pike MC, et al. 1983. The epidemiology of endometrial cancer in young women. Br J Cancer, 47:749-56. 
Horwitz R, Feinstein AR. 1978. Alternative analytic methods for case control studies of oestrogens and endometrial cancer. $N$ Engl J Med, 299:1089-94.

Hoda D, Perez DG, Loprinzi CL. 2003. Hot flashes in breast cancer survivors. Breast $J, 9: 431-8$.

Hyder SM, Chiappetta C, Stancel GM. 2001. Pharmacological and endogenous progestins induce vascular endothelial growth factor expression in human breast cancer cells. Int J Cancer, 92:469-73.

Khan SA, Pace JE, Cox ML, et al. 1994. Climacteric symptoms in healthy middle-aged women. Br J Clin Pract, 48:240-2.

Kroiss R, Fentiman IS, Helmond FA, et al. 2005. The effect of tibolone in postmenopausal women receiving tamoxifen after surgery for breast cancer:a randomised, double-blind, placebo-controlled trial. Br J Obstet Gynaecol, 112:228.

Kronenberg F. 1990. Hot flashes:epidemiology and physiology. Ann N Y Acad Sci, 592:52-86; discussion 123-33.

Kronenberg F. 1994. Hot flashes: phenomenology, quality of life and search for treatment options. Exp Gerontol, 29:319-36.

Laan E, van Lunsen RH. 2001. The effects of tibolone on vaginal blood flow, sexual desire and arousability in postmenopausal women. Climacteric, 4:28-41.

Landgren MB, Coelingh Bennink HJT, et al. 2002. Dose-response analysis of effects of tibolone on climacteric symptoms. Br J Obstet Gynaecol, 109:1109-14.

LeBlanc ES, Janowsky J, Chan BKS, et al. 2001. HRT and cognition:systematic review and meta-analysis. N Engl J Med, 285:1489-99.

Leonetti HB, Longo S, Anasti JN. 1999. Transdermal progesterone cream for vasomotor symptoms and postmenopausal bone loss. Obstet Gynecol, 94:225-8.

Lobo RA, Rosen RC, Yang HM, et al. 2003. Comparative effects of oral esterified estrogens with and without methyl testosterone on endocrine profiles and dimensions of sexual function in postmenopausal women with hypoactive sexual desire. Fertil Steril, 79:1341-52.

Lokkegaard E, Pedersen AT, Laursen P, et al. 2002. The influence of hormone replacement therapy on the aging-related change in cognitive performance: analysis based on a Danish cohort study. Maturitas, 42:209-18

Loprinzi CL, Michalak JC, Quella SK. 1994. Megestrol acetate for the prevention of hot flashes. $N$ Engl J Med, 331:347-52.

Loprinzi, et al. 2006. Phase III comparison of depomedroxyprogesterone acetate to venlafaxine for managing hot flashes: North Central Cancer Treatment Group Trial N99C7. J Clin Oncol, 24:1409-14.

MacLennan AH, Lester S, Moore V. Oral estrogen replacement therapy versus placebo for hot flushes. Cochrane Database Syst Rev 2002; 1: CD002978.

McBee WL, Dailey ME, Dugan E, et al. 1997. Hormone replacement therapy and other potential treatments for dementias. Endocrinol Metab Clin North Am, 26:329-45.

Million Women Study Collaborators. 2003. Breast cancer and hormone-replacement therapy in the Million Woman Study. Lancet, 362:419-27

Million Women Study Collaborators. 2005. Endometrial cancer and hormone-replacement therapy in the Million Women Study. Lancet, 365:1543-51.

Modelska K, Cummings S. 2002. Tibolone for Postmenopausal Women: Systematic Review of Randomized Trials. J Clin Endocrinol Metab, 87:16-23

Mulnard RA, Cotman CW, Kawas C, et al. 2000. Estrogen replacement therapy for treatment of mild to moderate Alzheimer disease:a randomized controlled trial: Alzheimer's Disease Cooperative Study. JAMA, 283:1007-15.

Nachtigall LE. 1994. Comparative study:replens versus local estrogen in menopausal women. Fertil Steril, 61:178-80.

Naftolin F, Schneider H, Sturdee D. 2004. Guidelines for the hormone treatment of women in the menopausal transition and beyond:position statement by the executive committee of the International Menopause Society. Climacteric, 7:333-37.
Natale V, Albertazzi P, Zini M, et al. 2001. Exploration of cyclical changes in memory and mood in post menopause women taking sequential combined oestrogen and progestin preparations. BJOG, 108:286-90.

Nathorst-Böös J, Hammar M. 1997. Effect on sexual life-a comparison between tibolone and a continuous estradiol-norethisterone acetate regimen. Maturitas, 26:15-20

Paganini-Hill RR, Henderson BE. 1989. Endometrial cancer and patterns of use of oestrogen replacement therapy:a cohort study. Br J Cancer, 59:445-7.

Panjari M, Davis SR. 2007. DHEA therapy for women:effect on sexual function and wellbeing. Hum Reprod Update, 13:239-48

Pasqualini JR, Chetrite G, Blacker C, et al. 1996. Concentrations of estrone, estradiol, and estrone sulfate and evaluation of sulfatase and aromatase activities in pre- and postmenopausal breast cancer patients. $J$ Clin Endocrinol Metab, 81:1460-4.

Prestwood KM, Kenny AM, Kleppinger A, et al. 2003. Ultralowdose micronized 17beta-estradiol and bone density and bone metabolism in older women:a randomized controlled trial. JAMA, 290:1042-8.

Pukkala E, Tulenheimo-Silfvast A, Leminem A. 2001. Incidence of cancer among women using long versus monthly cycle HRT Finland 1994-1997. Cancer Causes Control, 12:111-15.

Quella SK, Loprinzi CL, Sloan JA, et al. 1998. Long term use of megestrol acetate by cancer survivors for the treatment of hot flashes. Cancer, $82: 1784-8$.

Riphagen F. 2000. Intrauterine application of progestins in hormone replacement therapy. Climacteric, 3:199-211.

Ross LA, Adler EM, Cawood EHH, et al. 1999. Psychological effects of hormone replacement therapy:a comparison of tibolone and a sequential estrogen therapy. J Psychosom Obstet Gynaecol, 20:88-96.

Rossouw JE, Anderson GL, Prentice RL, et al. 2002. Risks and benefits of estrogen plus progestin in healthy postmenopausal women:Principal results from the Women's Health Initiative randomized controlled trial. JAMA, 288:321-33.

Royal Australian and New Zealand College of Obstetricians and Gynaecologists. Writing Group for the Consensus Panel. 2004. Advice to medical practitioners regarding the use of postmenopausal hormone therapy. [online] Accessed September 2006 URL: http://www.ranzcog.edu. au/media/pdfs/HTAdviceStatement12th\%20Aug.pdf.

Sarrel P, Dobay B, Wiita B. 1998. Estrogen and estrogen-androgen replacement in postmenopausal women dissatisfied with estrogen only therapy:sexual behaviour and neuroendocrine responses. $J$ Reprod Med, 43:847-56.

Schiff I, Tulchinsky D, Cramer D, et al. 1980. Oral medroxyprogesterone in the treatment of postmenopausal symptoms. JAMA, 244:1443-5.

Schindler A. 2003. Differential effects of progestins on hemostasis. Maturitas; 46(Suppl 1):S31-7.

Schindler AE, Canpagnoli C, Druckmann R, et al. 2003. Classification and pharmacology of progestins. Maturitas, 46(Suppl 1):S7-S16.

Sherwin BB, Gelfand MM, Brender W. 1985. Androgen enhances sexual motivation in females:a prospective crossover study of sex steroid administration in the surgical menopause. Psychosom Med, 47:33951.

Sherwin B. 1991. The impact of different doses of estrogen and progestin on mood and sexual behavior in postmenopausal women. J Clin Endocrinol Metab, 72:336-43.

Shifren JL. 2002. Androgen deficiency in the oophorectomized woman. Fertil Steril, 77(Suppl 4):S60-2

Shumaker SA, Legault C, Rapp SR, et al. 2003. Estrogen plus progestin and the incidence of dementia and mild cognitive impairment in postmenopausal women:a randomized controlled trial. JAMA, 289:2651-62.

Shumaker SA, Legault C, Kuller L, et al. 2004. Conjugated equine estrogens and incidence of probable dementia and mild cognitive impairment in postmenopausal women:Women's Health Initiative Memory Study. JAMA, 291:2947-58.

Simon JA, Klaiber E, Wiita B, et al. 1996. Double-blind comparison of two doses of estrogen and estrogen-androgen therapy in naturally postmenopausal women:neuroendocrine, psychological, and psychosomatic effects. Fertil Steril, 66:S71. 
Simpson E, Rubin G, Clyne C, et al. 2000. The role of local estrogen biosynthesis in males and females. Trends Endocrinol Metab, 11:184-8.

Slowinska-Srzednicka J, Zgliczynski S, Jeske W, et al. 1992. Transdermal 17 beta-estradiol combined with oral progestin increases plasma levels of insulin-like growth factor-I in postmenopausal women. J Endocrinol Invest, 15:533-8.

Somboonporn W, Davis S, Seif MW, et al. 2005. Testosterone for peri- and postmenopausal women. Cochrane Database of Systematic Reviews. Issue 4. Art. No.:CD004509. DOI:10.1002/14651858.CD004509. pub2.

The North American Menopause Society. 2005. The role of testosterone therapy in postmenopausal women:position statement of The North American Menopause Society. Menopause, 12:497-511.

Traish A, Guay AT, Spark RF. 2007. Testosterone Therapy in Women Study Group. Are the Endocrine Society's Clinical Practice Guidelines on Androgen Therapy in Women misguided? A commentary. $J$ Sex Med, 4:1223-34.

Valdivia I, Campodonico I, Tapia A, et al. 2004. Effects of tibolone and continuous combined hormone therapy on mammographic breast density and breast histochemical markers in postmenopausal women. Fertil Steril, 81:617-23.

Warren R. 2004. Hormones and mammographic breast density. Maturitas, 49:67-78.
Watts NB, Notelovitz M, Timmons MC, et al. 1995. Comparison of oral estrogens and estrogens plus androgen on bone mineral density, menopausal symptoms, and lipid-lipoprotein profiles in surgical menopause. Obstet Gynecol, 85:529-37.

Weiderpass E, Adami HO, Baron JA, et al. 1999. Risk of endometrial cancer following estrogen replacement with and without progestins. $J$ Natl Cancer Inst, 91:1131-7.

Wells M, Sturdee DW, Barlow DH, et al. 2002. Effect on endometrium of long term treatment with continuous combined estrogen/progestin replacement therapy; follow up study. BMJ, 325:239-42.

Wierman ME, Basson R, Davis SR, et al. 2006. Androgen therapy in women: an Endocrine Society Clinical Practice guideline. J Clin Endocrinol Metab, 91:3697-710.

WHO. 1966. Technical report series:menopause. 7:236-42.

Wisniewski A, Nguyen TT, Dobs AS. 2002. Evaluation of high-dose estrogen and high-dose estrogen plus methyltestosterone treatment on cognitive task performance in postmenopausal women. Horm Res, 58:150-5.

Wren BG, Champion SM, Willetts K, et al. 2003. Transdermal progesterone and its effect on vasomotor symptoms, blood lipid levels, bone metabolic markers, moods, and quality of life for postmenopausal women. Menopause, 10:13-8. 